\title{
Review \\ Sensitivity of Staphylococcal Biofilm to Selected Compounds of Plant Origin
}

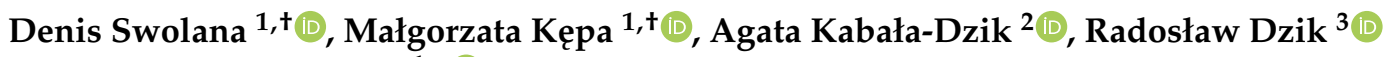 \\ and Robert D. Wojtyczka $1, * \mathbb{B}$
}

1 Department of Microbiology and Virology, Faculty of Pharmaceutical Sciences in Sosnowiec, Medical University of Silesia in Katowice, ul. Jagiellońska 4, 41-200 Sosnowiec, Poland; dswolana@sum.edu.pl (D.S.); mkepa@sum.edu.pl (M.K.)

2 Department of Pathology, Faculty of Pharmaceutical Sciences in Sosnowiec, Medical University of Silesia in Katowice, ul. Ostrogórska 30, 41-200 Sosnowiec, Poland; adzik@sum.edu.pl

3 Department of Biosensors and Processing of Biomedical Signals, Faculty of Biomedical Engineering, Silesian University of Technology, ul. Roosevelta 40, 41-800 Zabrze, Poland; radoslaw.dzik@gmail.com

* Correspondence: rwojtyczka@sum.edu.pl; Tel.: +48-32-364-1620

+ These authors contributed equally to this work.

\section{check for} updates

Citation: Swolana, D.; Kępa, M.; Kabała-Dzik, A.; Dzik, R.; Wojtyczka, R.D. Sensitivity of Staphylococcal Biofilm to Selected Compounds of Plant Origin. Antibiotics 2021, 10, 607. https: / / doi.org/10.3390/ antibiotics 10050607

Academic Editors: Débora C. Coraça-Huber, Eliana Aparecida de Rezende Duek and Marina Angélica Marciano da Silva

Received: 22 March 2021

Accepted: 19 May 2021

Published: 20 May 2021

Publisher's Note: MDPI stays neutral with regard to jurisdictional claims in published maps and institutional affiliations.

Copyright: (c) 2021 by the authors. Licensee MDPI, Basel, Switzerland. This article is an open access article distributed under the terms and conditions of the Creative Commons Attribution (CC BY) license (https:// creativecommons.org/licenses/by/ $4.0 /)$.

\begin{abstract}
Staphylococcus epidermidis is a bacterium that belongs to the human microbiota. It is most plentiful on the skin, in the respiratory system, and in the human digestive tract. Moreover, it is the most frequently isolated microorganism belonging to the group of Coagulase Negative Staphylococci (CoNS). In recent years, it has been recognized as an important etiological factor of mainly nosocomial infections and infections related to the cardiovascular system. On the other hand, Staphylococcus aureus, responsible for in-hospital and out-of-hospital infections, is posing an increasing problem for clinicians due to its growing resistance to antibiotics. Biofilm produced by both of these staphylococcal species in the course of infection significantly impedes therapy. The ability to produce biofilm hinders the activity of chemotherapeutic agents - the only currently available antimicrobial therapy. This also causes the observed significant increase in bacterial resistance. For this reason, we are constantly looking for new substances that can neutralize microbial cells. In the present review, 58 substances of plant origin with antimicrobial activity against staphylococcal biofilm were replaced. Variable antimicrobial efficacy of the substances was demonstrated, depending on the age of the biofilm. An increase in the activity of the compounds occurred in proportion to increasing their concentration. Appropriate use of the potential of plant-derived compounds as an alternative to antibiotics may represent an important direction of change in the support of antimicrobial therapy.
\end{abstract}

Keywords: antimicrobial activity; anti-biofilm; plants; Staphylococcus epidermidis; Staphylococcus aureus

\section{Introduction}

A biofilm is a population of bacteria that grows on a specific surface (biotic-e.g., tissue or abiotic - e.g., catheter). Bacterial cells, which make up only 10 to $15 \%$ of the volume of this structure, are surrounded by the extracellular matrix, making up the remaining 85-90\% and consisting of sugars, proteins and extracellular DNA (eDNA) [1,2]. Compared to bacteria living in the planktonic form, microorganisms with the ability to produce biofilm can be up to 1000 times more resistant to the action of antibiotics and antimicrobial agents [3].

Eighty percent of the nosocomial infections are related to bacteria living in biofilm structures. Despite the multiplication of medical procedures to prevent infection, more and more bacterial strains are gaining resistance to the next groups of antibiotics. Pseudomonas aeruginosa, which develops a highly resistant biological layer in the respiratory tract of patients with cystic fibrosis, is among the best-known species of bacteria that produce biofilm and are responsible for infections within the human body [4]. Other examples may be bacteria of the Staphylococcus 
genus, including Staphylococcus epidermidis, which is statistically the most common cause of infective endocarditis and nosocomial sepsis [5]. Moreover, a Staphylococcus aureus resistant to methicillin (MRSA) is responsible for biofilm infections that are more difficult to treat and requires more intensive care [4].

Infections with the above-mentioned microorganisms have been observed in cases of heart valves, orthopedic implants, intravascular catheters, artificial heart, pacemakers, vascular prostheses, cerebrospinal fluid fistulas, urinary catheters, eye prostheses and contact lenses, and intrauterine contraceptive devices [6]. In most cases, they occur as a result of contamination of the biomaterial at the time of implantation or as a result of transient bacteremia [7]. From a medical point of view, both commensal and pathogenic microorganisms form biofilm-like conglomerates that are bound to the epithelial or endothelial lining, embedded in a layer of pulmonary, intestinal or vaginal mucus, attached to teeth or the surface of a medical implant, or formed intracellularly [6]. The surface of the human body, especially the skin, has a microbiota dominated by S. epidermidis, which can cause infection, as an opportunistic strain [8].

Transmission may also occur in the course of opening the patient's gastrointestinal tract or respiratory system. This may be because implants are often used during such surgeries [9]. Bacteria can infect implants quickly upon contact and form a biofilm on their surface, with serious implications for patients. Biofilm-producing microorganisms are much less susceptible to antibiotics and the host's immune system compared to the planktonic-growing bacteria. Treating such infections is difficult and often poses a challenge to clinicians in the hospital. It also leads to serious complications, i.e., chronic or recurrent infections [6].

Over the past 80 years, many antibiotics have been introduced to the market and have had a positive impact on our lives. For example, in the U.S. alone, nearly 3300 metric tons of antibiotics were sold, of which nearly 1500 tons were penicillins and 500 tons were sulfa drugs, in 2011 alone. The use of antimicrobials in animals may contribute to the emergence of bacterial resistance. That can be transferred to humans, reducing the effectiveness of antimicrobial drugs. Already, AMR (antimicrobial resistance) is recognized as a growing global threat [10].

Treatment of biofilm-associated infections requires relatively high doses and a longterm antimicrobial drug regimen. For this reason, there is a non-zero risk of developing antimicrobial resistance (AMR). Because of these, it becomes imperative to search for more effective biofilm inhibiting agents [11].

\section{Staphylococcal Biofilm}

Staphylococcus aureus and coagulase-negative staphylococci are considered the most common cause of biofilm-forming infections [12]. Approximately 20-25\% of the human population carries Staphylococcus aureus, and it has been shown that there is a strong causal link between nasal carriage and an increased risk of nosocomial infection in these individuals. Due to the increasing share of this pathogen in infections, their rapid development, and the possibility of transforming into a chronic, persistent and recurrent infection, this microorganism deserves special attention [13].

In addition to many pathogenic factors of cutaneous staphylococcus, such as the ability to produce toxins, excluding the increased resistance of these bacteria to the antibiotic treatment used, as well as the possibility of secreting immune-evasion proteins, difficulties in treatment and the increasing incidence of chronic infections are conditioned by its ability to produce biofilm [14-16]. Most authors describe the process of biofilm formation as three main stages: adhesion, maturation, and dispersion [14]. The stages of biofilm formation are shown in Figure 1. 


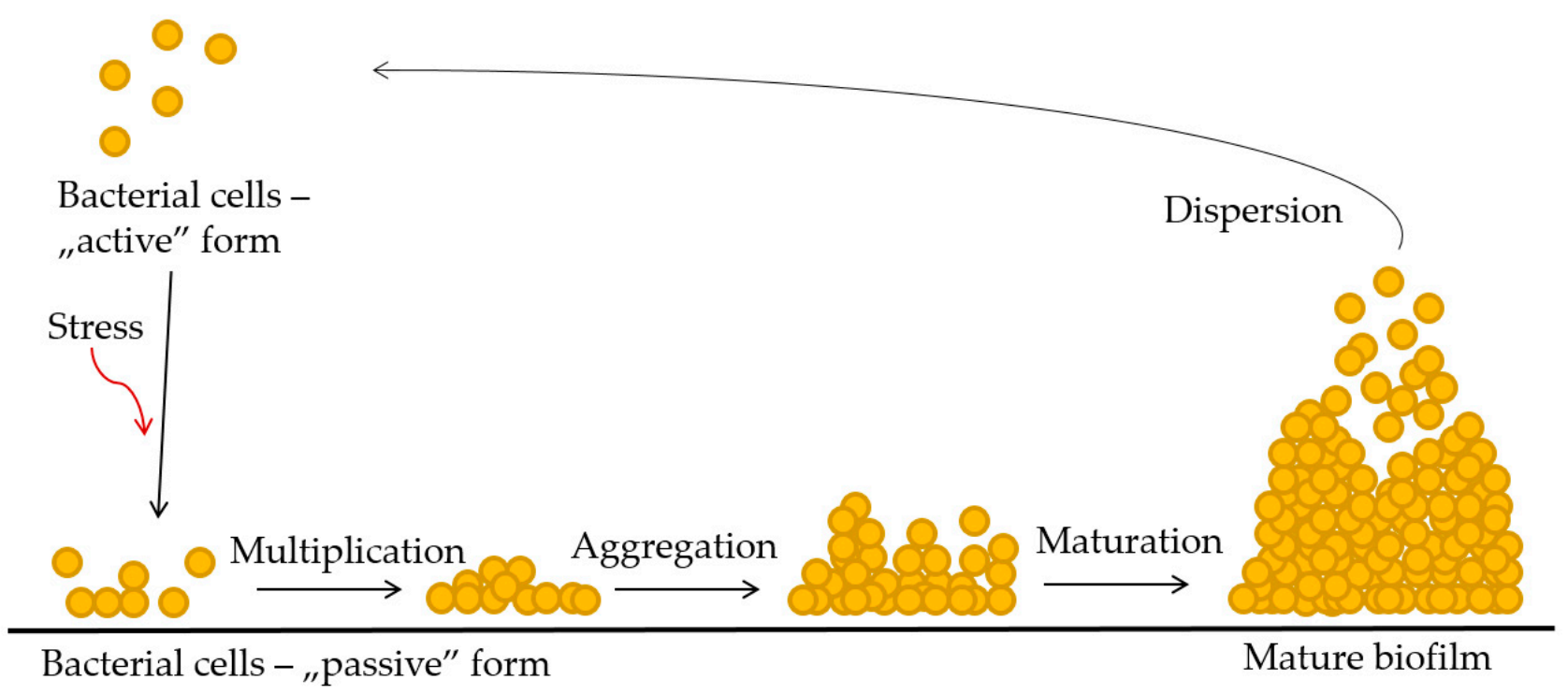

Figure 1. Stages of biofilm formation in staphylococci [4].

Although biofilm can be formed from one cell, environmental conditions, such as the diversified supply of oxygen, nutrients, or electron acceptors determine the diversity of the cell population [13].

\section{Plant-Derived Antibiofilm Substances}

The development of new antibiotics allows their use in the course of patient treatment. However, the discovery of antibiotics is becoming increasingly difficult. It is therefore necessary to search for unconventional treatment strategies as well as alternatives to these common antimicrobial agents. In addition to bacteriophage therapy, photodynamic treatment and numerous derivatives of chemical compounds, raw materials of natural origin remain an important source of therapeutic substances. Plants and microorganisms produce a wide range of diverse secondary metabolites that serve as defenses against pathogens. This is the source of many substances against a variety of bacterial virulence factors [17].

Already, more than $80 \%$ of medicinal substances are directly derived from natural substances or have been produced from natural products. Available data indicate that about $50 \%$ of pharmaceuticals contain active substances synthesized from previously identified or isolated compounds derived from plants or animals [18].

Active agents found in plants can be divided into two main groups. The first includes products of primary metabolism, including carbohydrates (sugars, mucilages), fats (fatty acids, phytosterols), proteins, amino acids, vitamins, enzymes, and pigments. The second group consists of secondary metabolism products, including glycosides, terpenes, saponins, polyphenols, alkaloids, essential oils, organic acids, and others [19]. Antimicrobial activity is mainly exhibited by secondary metabolites present in substances of plant origin. They have a wide range of action, depending on the species of plant from which they originate or the climate of the country where it occurs [20]. Depending on their structure, they exhibit various biological properties ranging from antioxidant, antibacterial, antifungal to modulating enzymatic activity. Considering the above plants are excellent sources of novel antimicrobial compounds [21].

Phenols and polyphenols, as the simplest phytochemicals, have a strong ability to bind various macromolecules such as proteins or glycoproteins and in this form are toxic to microorganisms. They can also enhance the effects of antibiotics, especially against Grampositive bacteria [22]. Quinones are ubiquitous and highly reactive organic compounds. The free radicals they produce, form irreversible complexes with microbial proteins. In turn, anthraquinones inactivate bacterial adhesins and polypeptides, leading to bacterial 
cell dysfunction [20]. Flavonoids are a structurally diverse group of compounds produced by plants, among others, in response to bacterial infection. Their chemical structure differentiates them into: flavones, flavonols, flavanones, flavanonols, anthocyanides, isoflavones, and chalcones. The activity of these compounds is due to their ability to form complexes with proteins and bacterial membranes, induce oxidative stress, or inhibit electron transport in the bacterial respiratory chain $[20,23]$. Tannins are polymeric phenolic substances that exhibit antimicrobial activity through inactivation of enzymes, adhesins, and transport proteins, and antiperoxidative properties [20]. Terpenes and terpenoids are in turn produced by plants to interact with other organisms. Their high concentrations are also found in essential oils. In addition to the aforementioned characteristics, antimicrobial and antibiofilm activities of these substances have also been demonstrated, either by the mechanism of additive or synergistic action with other antimicrobial drugs [20,24]. The proven antimicrobial activity of coumarins is mainly due to their ability to bind to the beta subunit of DNA gyrase and block the ATPase activity of bacteria. They are composed of a combined benzene and pyrone ring $[20,25]$. Alkaloids are compounds containing a nitrogen atom in their structure. Their antimicrobial activity is based on disruption of growth, bacterial proliferation, accumulation in the bacterial cell, and DNA intercalation [20]. The diverse mechanism of action and numerous in vitro studies for the above-mentioned groups of compounds open up a wide range of possibilities for the use of these antimicrobial agents in therapy, given the ever-increasing resistance to commonly used antibiotics [22].

Table 1 presents the plant natural compounds discussed in the literature that may find application in antimicrobial and antibiofilm therapy. The information was collected from scientific papers published between 2010 and 2020, presenting the use of plant natural compounds in counteracting biofilm formation. Substances from organisms included in other systematic groups were excluded.

Table 1. Plant-derived antimicrobial substances with antibiofilm activity.

\begin{tabular}{|c|c|c|c|c|c|}
\hline No & Substance & Source & Systematic Group & Scope of Activity & Ref. \\
\hline 1. & 1-monolaurin & coconut oil & glycerides & $\begin{array}{c}\text { Inhibition of biofilm formation at } 500 \mu \mathrm{g} / \mathrm{mL} \text { at } \\
96.78 \% \text {, biofilm eradication at } 500 \mu \mathrm{g} / \mathrm{mL} \text { among } \\
\text { clinical isolates of S. epidermidis (the collection of } \\
\text { Microbiology Laboratory Faculty of Medicine, Public } \\
\text { Health, and Nursing UGM) at } 68.16 \%\end{array}$ & [26] \\
\hline 2. & Cinnamaldehyde & $\begin{array}{c}\text { essential oil of } \\
\text { Cinnamomum Scheffer }\end{array}$ & aldehydes & $\begin{array}{c}\text { Inhibition of } S \text {. aureus ATCC } 25923 \text { biofilm formation } \\
\text { at a concentration of } 0.5 \mathrm{mg} / \mathrm{mL} \text { with a decrease of } \\
4 \text { logarithmic values and the ability to eliminate } \\
\text { mature biofilm approximately } 100 \text {-fold at a } \\
\text { concentration of } 0.5 \mathrm{mg} / \mathrm{mL}\end{array}$ & [27] \\
\hline 3. & Eugenol & Dianthus caryophyllus L. & terpenes & $\begin{array}{c}\text { MIC }=0.04 \% \text {; reduction by more than } 50 \% \text { of MRSA } \\
\text { (Culture Collection of Antimicrobial Resistant } \\
\text { Microbes, Seoul, Korea) and MSSA ATCC } 29213 \\
\text { biofilm growth in vitro at } 1 / 2 \text { MIC concentration }\end{array}$ & {$[28]$} \\
\hline 4. & Nerolidol & Pogostemon heyneanus & terpenes & $\begin{array}{c}\text { MIC }=0.025 \% \text {; growth reduction of immature MRSA } \\
\text { (clinical strains) biofilms at } 1 / 2 \mathrm{MIC} \text { and } 1 / 4 \mathrm{MIC} \text { at } \\
88 \% \text {, while inhibition of mature MRSA (clinical } \\
\text { strains) biofilms at } 1 / 2 \mathrm{MIC} \text { and } 1 / 4 \mathrm{MIC} \text { at } 85 \%\end{array}$ & [29] \\
\hline 5. & $\begin{array}{l}\text { Sesquiterpenes and } \\
\text { diterpenes }\end{array}$ & $\begin{array}{c}\text { oleoresin of Copaifera } \\
\text { duckei }\end{array}$ & terpenes & $\begin{array}{l}\mathrm{IC}_{50} \text { value for mature } S \text {. aureus (clinical isolate) } \\
\text { biofilms exposed to oleoresin }=21.85 \mu \mathrm{g} / \mathrm{mL} \text {; MBIC } \\
\text { for } \text { S. epidermidis (water isolate) }=12.50 \mu \mathrm{g} / \mathrm{mL} \text {, } \\
\text { MBIC for S. aureus (clinical isolate) between } 0.78 \text { and } \\
100.00 \mu \mathrm{g} / \mathrm{mL}\end{array}$ & [30] \\
\hline 6. & $\begin{array}{l}\text { Methanol extract } \\
\text { from aerial parts of } \\
\text { Anthemis stiparum } \\
\text { subsp. Sabulicola }\end{array}$ & $\begin{array}{c}\text { aerial parts of Anthemis } \\
\text { stiparum subsp. } \\
\text { sabulicola }\end{array}$ & terpenes & $\begin{array}{c}\text { MIC }=1.56 \mathrm{mg} / \mathrm{mL} \text { for } S \text {. aureus subsp. aureus ATCC } \\
25923 ; 59.06 \% \text { inhibition on biofilm growth at the } \\
\text { MIC concentration; MIC }=25 \mathrm{mg} / \mathrm{mL} \text { for } S \text {. } \\
\text { epidermidis MU 30, 30.43\% inhibition on biofilm } \\
\text { growth at the MIC concentration }\end{array}$ & [31] \\
\hline
\end{tabular}


Table 1. Cont.

\begin{tabular}{|c|c|c|c|c|c|}
\hline No & Substance & Source & Systematic Group & Scope of Activity & Ref. \\
\hline 7. & $\begin{array}{l}\text { Organic extract of } \\
\text { Prunus cerasoides }\end{array}$ & Prunus cerasoides & diterpenes & $\begin{array}{c}\text { MIC }=5 \mathrm{mg} / \mathrm{mL} ; \text { inhibition of approximately } 50 \% \text { of } \\
\text { mature } S . \text { aureus MTCC } 740 \text { biofilm growth; } \\
\text { MIC }=10 \mathrm{mg} / \mathrm{mL} \text { for } S . \text { epidermidis MTCC } 435 ; \\
\text { MIC }=1 \mathrm{mg} / \mathrm{mL} \text { for MRSA (clinical strain) }\end{array}$ & {$[32]$} \\
\hline 8. & Andrographolide & Andrographis paniculata & terpenoids & $\begin{array}{l}\text { Inhibition of S. aureus MTCC } 96 \text { biofilm growth by } \\
\text { about } 45 \% \text { on the polystyrene surface after } 24 \mathrm{~h} \text { of } \\
\text { exposure to the compound at a concentration of } \\
50 \mu \mathrm{g} / \mathrm{mL}\end{array}$ & [33] \\
\hline 9. & Celastrol & $\begin{array}{l}\text { Extract of Tripterygium } \\
\text { wilfordii and Celastrus } \\
\text { regelii }\end{array}$ & terpenoids & $\begin{array}{l}\text { Inhibition of biofilm formation by } 25.5-85.07 \% \text {, } \\
\text { eradication of mature biofilm by } 40.5-80.2 \% \text { for } \\
\text { S. aureus (MSSA) ATCC 29213; inhibition of biofilm } \\
\text { formation by } 27-89.3 \% \text {, eradication of mature biofilm } \\
\text { by } 49.5-82.8 \% \text { for S. aureus (MRSA) clinical strains }\end{array}$ & {$[34]$} \\
\hline 10. & $\begin{array}{l}\text { Emulsion containing } \\
\text { resin acids }\end{array}$ & $\begin{array}{l}\text { Norway spruce-Picea } \\
\text { abies }\end{array}$ & terpenoids & $\begin{array}{c}90.8 \% \pm 8.4 \% \text { growth inhibition of } S . \text { aureus MRSA } \\
\text { (ATCC BAA-44); significant increase in eradication } \\
\text { and reduction in biofilm formation for S. aureus } \\
\text { Mu50 and S. epidermidis ET013 }\end{array}$ & [35] \\
\hline 11. & $\begin{array}{l}(+) \text {-dehydroabietic } \\
\text { acid }\end{array}$ & $\begin{array}{l}\text { oleoresin from a tree of } \\
\text { the genus Picea }\end{array}$ & terpenoids & $\begin{array}{c}\text { MIC }=21 \mathrm{mg} / \mathrm{L} \text { for } S . \text { aureus ATCC } 25923 \text {; significant } \\
\text { inhibition of biofilm formation }\left(\mathrm{IC}_{50}=8.35 \mathrm{mg} / \mathrm{L}\right) \\
\text { and action on biofilm-forming S. aureus } \\
\left(\mathrm{IC}_{50}=33.9 \mathrm{mg} / \mathrm{mL}\right)\end{array}$ & {$[36]$} \\
\hline 12. & Phosprenil & $\begin{array}{l}\text { conifer needles of fir } \\
\text { (Abiessibirica) or pine } \\
\quad \text { (Pinussylvestris) }\end{array}$ & prenoles & $\begin{array}{l}\text { Approximately 2-fold inhibition of S. aureus ATCC } \\
6538 \text { and a clinical strain } 010 \mathrm{Ng} \text {, biofilm growth at } \\
\text { concentrations of } 7.5-30 \mathrm{mg} / \mathrm{mL}\end{array}$ & [37] \\
\hline 13. & Carvacrol & Plectranthus amboinicus & phenols & $\begin{array}{l}\text { MIC }=0.25 \mathrm{mg} / \mathrm{mL} \text { for } S \text {. aureus OVRSA and ATCC } \\
6538 ; \text { antibiofilm activity against } S . \text { aureus ATCC } \\
6538 \text { at } 0.25 \mathrm{mg} / \mathrm{mL} \text {; biofilm reduction ability at all } \\
\text { carvacrol concentrations tested }(0.062 \text { to } 4 \mathrm{mg} / \mathrm{mL})\end{array}$ & {$[38]$} \\
\hline 14. & Carvacrol & oregano oil & phenols & $\begin{array}{l}\text { Reduction in } S \text {. aureus BMA/FR/032/0074 biofilm } \\
\text { production at a concentration of } 0.50-1.00 \mathrm{mM}\end{array}$ & [39] \\
\hline 15. & Carvacrol & $\begin{array}{l}\text { essential oils of } \\
\text { oregano, thyme }\end{array}$ & phenols & $\begin{array}{l}\text { Ability to approximately } 1000 \text {-fold eliminate mature } \\
\text { S. aureus ATCC } 25923 \text { biofilm at } 0.5 \mathrm{mg} / \mathrm{mL} \text { and } \\
\text { inhibit its formation at the same concentration, with } \\
\text { a decrease in CFU of } 1,000,000 / \mathrm{mL}\end{array}$ & [27] \\
\hline 16. & Thymol & $\begin{array}{l}\text { essential oils of Thymus } \\
\text { and savory }\end{array}$ & phenols & $\begin{array}{c}\text { Ability to approximately } 1000 \text {-fold eliminate mature } \\
\text { S. aureus ATCC } 25923 \text { biofilm at a concentration of } \\
0.5 \mathrm{mg} / \mathrm{mL} \text { and inhibit its formation at a } \\
\text { concentration of } 0.5 \mathrm{mg} / \mathrm{mL} \text { with a decrease of } \\
5 \text { logarithmic values }\end{array}$ & [27] \\
\hline 17. & Ellagic acid xyloside & Rubus ulmifolius & polyphenols & $\begin{array}{l}50 \% \text { inhibition of S. aureus (MSSA) osteomyelitis } \\
\text { isolate (UAMS- } 1 \text { ) biofilm formation at a } \\
\text { concentration of } 64 \mu \mathrm{g} / \mathrm{mL}\end{array}$ & {$[40]$} \\
\hline 18. & $\begin{array}{l}\text { Ellagic acid } \\
\text { rhamnoside }\end{array}$ & Rubus ulmifolius & polyphenols & $\begin{array}{l}50 \% \text { inhibition of S. aureus (MSSA) osteomyelitis } \\
\text { isolate (UAMS-1) biofilm formation at a } \\
\text { concentration of } 64 \mu \mathrm{g} / \mathrm{mL} \text {; capable of } 90 \% \\
\text { inhibition of biofilm formation at a concentration of } \\
128 \mu \mathrm{g} / \mathrm{mL}\end{array}$ & {$[40]$} \\
\hline 19. & Psychorubrine & Mitracarpus frigidus & quinones & $\begin{array}{c}\text { Inhibition of mature biofilms in approximately } 56 \% \\
\text { (MIC) and } 46 \% \text { (1/2 MIC) for S. aureus (MRSA) } \\
\text { ATCC } 33591 \text { and in } 84 \% \text { (MIC) and } 85 \%(1 / 2 \text { MIC) } \\
\text { for S. aureus (MRSA) ATCC } 33592\end{array}$ & [41] \\
\hline 20. & Aurantioglycoladine & $\begin{array}{l}\text { Clonostachys } \\
\text { candelabrum }\end{array}$ & quinones & $\begin{array}{c}\text { MIC }=64 \mu \mathrm{g} / \mathrm{mL} \text { for } S . \text { epidermidis ATCC } 35984 ; \\
\text { inhibition of biofilm production in } 55 \% \text { at a } \\
\text { concentration of } 256 \mu \mathrm{g} / \mathrm{mL}, \text { in } 51 \% \text { at } 64 \mu \mathrm{g} / \mathrm{mL} \text {, in } \\
19 \% \text { at } 32 \mu \mathrm{g} / \mathrm{mL} \text { and in } 10 \% \text { at } 16 \mu \mathrm{g} / \mathrm{mL} ; \\
\text { MIC }=300 \mu \mathrm{g} / \mathrm{mL} \text { for Staphylococcus aureus } \\
\text { DSM } 1104\end{array}$ & {$[42]$} \\
\hline
\end{tabular}


Table 1. Cont.

\begin{tabular}{|c|c|c|c|c|c|}
\hline No & Substance & Source & Systematic Group & Scope of Activity & Ref. \\
\hline 21. & Alpha-mangostin & $\begin{array}{l}\text { pericarp of Garcinia } \\
\text { mangostana L. (family } \\
\text { Clusiaceae) }\end{array}$ & xanthones & $\begin{array}{c}\text { Significant inhibition of S. aureus (MRSA) standard } \\
\text { isolate DMST } 20654 \text { biofilm formation in a } \\
\text { dose-dependent manner from } 1 / 16 \text { MIC to MIC; at } \\
\text { 1/2 MIC, inhibition of biofilm formation by } \\
\text { approximately } 70 \%\end{array}$ & [43] \\
\hline 22. & Xanthohumol & Humulus lupulus & chalcones & $\begin{array}{l}\text { Inhibition of S. aureus (clinical isolate T28.1) } \\
\text { biofilm-forming ability and ability to reduce existing } \\
\text { biofilm at a concentration of } 39 \mu \mathrm{g} / \mathrm{mL} \text { (MIC) }\end{array}$ & [44] \\
\hline 23. & Desmethylxanthohumol & Humulus lupulus & chalcones & $\begin{array}{l}\text { Inhibition of the biofilm-producing ability of } S \text {. } \\
\text { aureus (clinical isolate T28.1) at a concentration of } \\
4.9 \mu \mathrm{g} / \mathrm{mL}(1 / 2 \mathrm{MIC}) \text { and the ability to destroy an } \\
\text { existing biofilm at a concentration of } 2.45 \mu \mathrm{g} / \mathrm{mL} \\
(1 / 4 \mathrm{MIC})\end{array}$ & [44] \\
\hline
\end{tabular}

\begin{tabular}{|c|c|c|c|c|c|}
\hline 24. & Resveratrol & $\begin{array}{c}\text { Peanuts (Arachis } \\
\text { hypogea), blueberries } \\
\text { and cranberries } \\
\text { (Vacciniumspp.), } \\
\text { Japanese knotweed } \\
\text { (Polygonum cuspidatum), } \\
\text { grapevine (Vitis vinifera) }\end{array}$ & stilbenes & $\begin{array}{l}\text { MIC }=350 \mu \mathrm{g} / \mathrm{mL} \text {; inhibition of } S \text {. aureus (clinical } \\
\text { MRSA isolate) biofilm formation by approximately } \\
39.85 \% \text { at a concentration of } 100 \mu \mathrm{g} / \mathrm{mL}\end{array}$ & [45] \\
\hline 25. & Baicalin & $\begin{array}{c}\text { Astragalusmembranaceus } \\
\text { root }\end{array}$ & flavones & $\begin{array}{c}\text { Inhibition of } S \text {. aureus (SA002, isolated from the nose } \\
\text { swab of a pig with pneumonia) biofilm formation in } \\
\text { a dose-dependent manner, statistically significant } \\
\text { reduction in increase in MIC and } 5 \text { MIC }\end{array}$ & [46] \\
\hline 26. & $\begin{array}{l}\text { 5-hydroxy-3,7, } 4^{\prime}- \\
\text { trimethoxyflavone }\end{array}$ & $\begin{array}{l}\text { Chromolaena odorata } \\
\text { (Asteraceae) }\end{array}$ & flavones & $\begin{array}{c}\text { Inhibition of } S \text {. aureus ATCC } 29213(\mathrm{MSSA} \text {,) biofilm } \\
\text { production at a concentration of } 1 \mathrm{mg} / \mathrm{mL} \text {, with } \\
\text { activity greater than } 50 \% \text { after } 24 \mathrm{~h}\end{array}$ & [47] \\
\hline 27. & Luteolin & $\begin{array}{l}\text { broccoli, peppers, } \\
\text { thyme and celery }\end{array}$ & flavones & $\begin{array}{c}\text { MIC }=16 \mu \mathrm{g} / \mathrm{mL} \text { for } S \text {. aureus ATCC } 25923 ; \\
\text { MIC }=64 \mu \mathrm{g} / \mathrm{mL} \text { for two } \text { S. aureus clinical strains } \\
\text { from derived from raw goat milk; } \\
\text { concentration-dependent anti-biofilm activity } \\
\text { against } S \text {. aureus ATCC } 25923 \text { biofilm at } \\
\text { concentrations of } 1 / 8 \text { MIC and above; antibiofilm } \\
\text { activity of luteolin against dual-species biofilm of } \\
\text { S. aureus ATCC } 25923 \text { and L. monocytogenes ATCC } \\
19115 \text { (MIC } 32 \mu \mathrm{g} / \mathrm{mL} \text { ) at concentrations of } 1 / 4 \mathrm{MIC} \\
\text { and above }\end{array}$ & [48] \\
\hline 28. & Dihydrovogonin & $\begin{array}{l}\text { bird cherry extract } \\
\text { Prunus avium }\end{array}$ & flavones & $\begin{array}{l}\text { Inhibition of growth of planktonic form at } \\
\text { concentrations of } 125-500 \mu \mathrm{g} / \mathrm{mL} \text {; reduction in } \\
\text { S. aureus (CIP 53.154) biofilm mass correlated with a } \\
\text { decrease in the number of bacteria in the forming } \\
\text { biofilm in the concentration range of } 125-500 \mu \mathrm{g} / \mathrm{mL}\end{array}$ & [49] \\
\hline 29. & Moryna & figi, migdały & flavones & $\begin{array}{l}\text { Inhibition of biofilm formation and elimination of } \\
\text { the formed structure for clinical isolated cultures of } \\
\text { MRSA (MBIC }=281.83 \mu \mathrm{g} / \mathrm{mL} \text { ) and VRSA } \\
\qquad(\text { MBIC }=398.10 \mu \mathrm{g} / \mathrm{mL})\end{array}$ & [50] \\
\hline 30. & $\begin{array}{l}\text { Organic extract of } \\
\text { Prunus cerasoides }\end{array}$ & Prunus cerasoides & flavonoids & $\begin{array}{c}\text { MIC }=1 \mathrm{mg} / \mathrm{mL} \text { for } S \text {. aureus MTCC } 740 ; \\
\text { MIC = } 10 \mathrm{mg} / \mathrm{mL} \text { for S. epidermidis MTCC } 435 ; \\
\text { inhibition of mature S. aureus MTCC } 740 \text { biofilm at } \\
86.5 \mathrm{mg} / \mathrm{mL} \text { by approximately } 45 \%\end{array}$ & [32] \\
\hline 31. & Naringenin & $\begin{array}{l}\text { hemp (Cannabis sativa } \\
\text { L.) }\end{array}$ & flavonoids & $\begin{array}{l}\text { MIC }=512 \mu \mathrm{g} / \mathrm{mL} \text { for } S . \text { aureus clinical strain; } \\
\text { minimum biofilm eradication concentration } \\
\text { MBEC }=2048 \mu \mathrm{g} / \mathrm{mL}\end{array}$ & [51] \\
\hline 32. & Derriobtusone A & $\begin{array}{c}\text { root bark of } \\
\text { Lonchocarpus obtusus }\end{array}$ & flavonoids & $\begin{array}{l}\text { Rapid decrease in biomass and CFU of S. aureus JKD } \\
6008 \text { biofilm at concentrations of } 250 \text { and } 500 \mu \mathrm{g} / \mathrm{mL}\end{array}$ & [52] \\
\hline 33. & $\begin{array}{l}\text { Ethyl acetate fraction } \\
\text { of Vernonia condensata } \\
\text { leaf extract }\end{array}$ & $\begin{array}{l}\text { leaves of Vernonia } \\
\text { condensata }\end{array}$ & flavonoids & $\begin{array}{c}\text { Inhibitory effect of MIC, } 2 \text { MIC and } 4 \text { MIC } \\
\text { concentrations on adhesion of S. aureus (MSSA) } \\
\text { ATCC } 25923 \text { and S. aureus (MRSA) ATCC } \\
1485279 \text {-inhibition in the range from } 60 \% \text { to } 100 \%\end{array}$ & [53] \\
\hline
\end{tabular}


Table 1. Cont.

\begin{tabular}{|c|c|c|c|c|c|}
\hline No & Substance & Source & Systematic Group & Scope of Activity & Ref. \\
\hline 34. & Corilagin & $\begin{array}{l}\text { fruit of Terminalia } \\
\text { chebula Retz }\end{array}$ & tannins & $\begin{array}{l}\text { Decrease in cell adhesion for S. aureus ATCC 11632: } \\
\qquad \mathrm{IC}_{50}=3.18 \mu \mathrm{g} / \mathrm{mL}\end{array}$ & [54] \\
\hline 35. & Tannic acid & $\begin{array}{l}\text { Quercus infectoria G. } \\
\text { Olivier extract }\end{array}$ & tannins & $\begin{array}{l}\text { Inhibition of MRSA (NPRC R001-R047, clinical } \\
\text { strain) biofilm formation at MIC (0.13-0.50 } \mu \mathrm{g} / \mathrm{mL} \text { ) } \\
\text { and sub-MIC concentrations; inhibition of MSSA } \\
\text { (NPRC S001-S050, were isolated from nasal } \\
\text { specimens of healthy volunteers) biofilm formation } \\
\text { at MIC }(0.13-0.50 \mu \mathrm{g} / \mathrm{mL})\end{array}$ & {$[55]$} \\
\hline 36. & Hamamelitanin & $\begin{array}{c}\text { whISOBAX, witch } \\
\text { hazel extract } \\
\text { (Hamamelis virginiana) }\end{array}$ & tannins & $\begin{array}{l}\text { Reduction in S. epidermidis ATCC } 35984 \text { biofilm } \\
\text { formation by nearly } 50 \% \text { at a 1:26 dilution }\end{array}$ & [56] \\
\hline 37. & $\begin{array}{c}\text { Alopecuron } \mathrm{H}, \mathrm{I}, \mathrm{J}, \mathrm{K}, \\
\text { L, A, B, D, } \\
\text { soforaflavone G }\end{array}$ & $\begin{array}{l}\text { root of Sophora } \\
\text { alopecuroides }\end{array}$ & flavonostilbenes & $\begin{array}{l}\text { MIC } 6.25-3.125 \mu \mathrm{g} / \mathrm{mL} \text {; inhibition of S. epidermidis } \\
\text { ATCC } 35984 \text { biofilm formation; preventing biofilm } \\
\text { formation at lower concentrations without } \\
\text { bactericidal activity }\end{array}$ & [57] \\
\hline
\end{tabular}

Hyperforin in the

38. form of dicyclohexy-

lammonium

salt

\begin{tabular}{cccc} 
39. & Thyme oil & Thymus vulgaris & essential oils \\
\hline 40. & Essential oil & $\begin{array}{c}\text { hemp } \\
\text { (Cannabis sativa } \text { L. })\end{array}$ & essential oils \\
\hline 41. & $\begin{array}{c}\text { Essential oil from the } \\
\text { leaves and stem of } \\
\text { Plectranthus } \\
\text { amboinicus }\end{array}$ & Plectranthus amboinicus & essential oils \\
& & \\
\hline
\end{tabular}

42. Essential oil Rosmarinus officinalis L. essential oils
MBIC $=25 \mu \mathrm{g} / \mathrm{mL}$ for S. aureus (ATCC 29213; ATCC

43300 and Ig5-clinical isolate); inhibition of biofilm development by $21-45 \%$

MIC $=0.078 \%$ for S. aureus ATCC 25923; 71\%

reduction in S. aureus ATCC 25923 biofilm viability at a concentration corresponding to the MIC

$\mathrm{MBEC}=24 \mathrm{mg} / \mathrm{mL}$ for $\mathrm{S}$. aureus (MSSA) ATCC 29213

Hypericum perforatum phloroglucinols

Antibiofilm activity against $S$. aureus OVRSA and ATCC 6538 at $0.5 \mathrm{mg} / \mathrm{mL}$; inhibition potential against S. aureus ATCC 6538 at all essential oil concentrations tested $(0.062-4 \mathrm{mg} / \mathrm{mL})$

MIC 1.25-2.5 $\mu \mathrm{L} / \mathrm{mL}$ for S. aureus ATCC 9144; MIC $0.312-0.625 \mu \mathrm{L} / \mathrm{mL}$ for S. epidermidis S61; inhibition of S. epidermidis $\mathrm{S} 61$ biofilm production above $57 \%$ at a concentration of $25 \mu \mathrm{L} / \mathrm{mL}$; biofilm eradication at a concentration of $50 \mu \mathrm{L} / \mathrm{mL}$

\begin{tabular}{|c|c|c|c|c|c|}
\hline 43. & $\begin{array}{l}\text { Essential oil from the } \\
\text { aerial parts of } \\
\text { Anthemis stiparum } \\
\text { subsp. Sabulicola }\end{array}$ & $\begin{array}{l}\text { aerial parts of Anthemis } \\
\text { stiparum subsp. } \\
\text { sabulicola }\end{array}$ & essential oils & $\begin{array}{l}\text { Inhibition of biofilm formation of S. epidermidis MU } \\
30 \text { and S. aureus ATCC } 25923 \text { to } 29.17 \% \text { and } 8.25 \% \text {, } \\
\text { respectively, at a concentration of } 25 \mu \mathrm{L} / \mathrm{mL}\end{array}$ & [31] \\
\hline 44. & Essential oils & $\begin{array}{l}\text { Pogostemon heyneanus } \\
\text { and Cinnamomum } \\
\text { tamala }\end{array}$ & essential oils & $\begin{array}{c}\text { MIC }=2-6 \% \text {; inhibition of immature biofilms of } \\
\text { MRSA (clinical strains) at concentrations of } 3-0.5 \% \\
\text { with efficacy of } 55-80 \% \text {; for biofilms of mature } \\
\text { MRSA, inhibition of } 60-80 \%\end{array}$ & [29] \\
\hline 45. & $\begin{array}{l}\text { Ethanolic leaf extract } \\
\text { of Mangifera indica L. }\end{array}$ & $\begin{array}{l}\text { leaves of Mangifera } \\
\text { indica } L \text {. }\end{array}$ & tannins & $\begin{array}{l}\text { Reduction of mature biofilm of eight } \\
\text { Staphylococcus spp. strains from cows with mastitis } \\
\text { by ethanol extract at a concentration of } 45.3 \mathrm{mg} / \mathrm{mL}\end{array}$ & [61] \\
\hline 46. & Erianin & $\begin{array}{l}\text { Dendrobium } \\
\text { chrysotoxum }\end{array}$ & $\begin{array}{l}\text { natural bibenzyl } \\
\text { compound }\end{array}$ & $\begin{array}{l}\text { Significant decrease in S. aureus (strain Newman } \\
\text { D2C-ATCC 25904) biofilm formation at a } \\
\text { concentration of } 64 \mu \mathrm{g} / \mathrm{mL}\end{array}$ & [62] \\
\hline 47. & $\begin{array}{l}\text { Chilean tree fruit } \\
\text { extract of Arrayan } \\
\text { and Peumo }\end{array}$ & $\begin{array}{l}\text { Arrayan [Luma apiculata } \\
\text { (DC.) Burret.] and } \\
\text { Peumo [Cryptocarya } \\
\text { alba (Molina) Looser] }\end{array}$ & $\begin{array}{c}\text { flavonols, } \\
\text { anthocyanins }\end{array}$ & $\begin{array}{c}\text { Higher activity of Arrayan extract } \\
\left(\mathrm{IC}_{50}=0.229 \pm 0.017 \mathrm{mg} / \mathrm{mL}\right) \text { compared to Peumo } \\
\text { extract }\left(\mathrm{IC}_{50}=0.473 \pm 0.028\right) \text { against biofilm of } \\
\text { S. aureus ATCC } 25923\end{array}$ & [63] \\
\hline 48. & $\begin{array}{l}\text { Polyphenolic extracts } \\
\text { from cladodes }\end{array}$ & $\begin{array}{l}\text { Opuntia ficus-indica } \\
\text { (L.)Mill. }\end{array}$ & $\begin{array}{l}\text { phenolic acids and } \\
\text { flavonols }\end{array}$ & $\begin{array}{l}\text { Significant inhibition of } S \text {. aureus ATCC } 35556 \\
\text { biofilm formation by extracts from mature and } \\
\text { immature clades at a concentration of } 1500 \mu \mathrm{g} / \mathrm{mL}\end{array}$ & [64] \\
\hline
\end{tabular}


Table 1. Cont.

\begin{tabular}{|c|c|c|c|c|c|}
\hline No & Substance & Source & Systematic Group & Scope of Activity & Ref. \\
\hline 49. & $\begin{array}{c}\text { Extracts of Tunisian } \\
\text { varieties of Olea } \\
\text { europaea L., i.e., } \\
\text { "Chetoui", "Meski", } \\
\text { "Oueslati" and } \\
\text { "Jarboui" }\end{array}$ & Olea europaea L. & $\begin{array}{l}\text { phenols and } \\
\text { flavonoids }\end{array}$ & $\begin{array}{l}\text { Best antibiofilm activity of Chetoui and Meski } \\
\text { extracts against S. aureus strains (MRSA and S. aureus } \\
\text { ATCC } 25923 \text { ) with inhibition values }>50 \% \text { at MIC } \\
\text { doses and } 72-89.8 \% \text { at doses of } 2 \text { MIC; good } \\
\text { antibiofilm activity of Jarboui and Oueslati extracts } \\
\text { against tested bacterial S. aureus strains (MRSA and } \\
\text { S. aureus ATCC } 25923 \text { ) in the range from } 54.5 \text { to } \\
83.8 \% \text { at the concentration of } 2 \text { MIC }\end{array}$ & [65] \\
\hline 50 & $\begin{array}{l}\text { Cheleritrin, } \\
\text { sanguinarine }\end{array}$ & $\begin{array}{l}\text { Krameria lappacea, } \\
\text { Aesculus hippocastanum } \\
\text { and Chelidonium majus }\end{array}$ & flavonoids, alkaloids & $\begin{array}{l}1.3 \text { to } 5.5 \text { times inhibition of mature } S \text {. aureus ATCC } \\
6538 \mathrm{P} \text { and } S \text {. epidermidis ATCC } 35984 \text { biofilm } \\
\text { formation and eradication; } \mathrm{EC}_{50} \text { of cheleritrin for } \\
\text { S. aureus (ATCC } 6538 \mathrm{P} \text { reference } \\
\text { strain) }-15.2 \pm 2.3 \mu \mathrm{M} \text {, for } S \text {. epidermidis ATCC } \\
35984-8.6 \pm 0.4 \mu \mathrm{M} \text {; } \mathrm{EC}_{50} \text { of sanguinarine for } \\
\text { S. aureus ATCC } 6538 \mathrm{P}-24.5 \pm 3.6 \mu \mathrm{M} \text {, for } \\
\text { S. epidermidis ATCC } 35984-4.4 \pm 1.3 \mu \mathrm{M}\end{array}$ & [66] \\
\hline 51. & Alcoholic extract & $\begin{array}{l}\text { Cytinus hypocistis and } \\
\text { Cytinus ruber }\end{array}$ & flavanoids, phenols & $\begin{array}{c}\text { Inhibition of biofilm formation in } 60-80 \% \text { at } 1 / 2 \text { MIC } \\
\text { for S. epidermidis ATCC } 35984\end{array}$ & [67] \\
\hline 52. & Ethanol extract & $\begin{array}{l}\text { leaves of Moringa } \\
\text { stenopetala }\end{array}$ & $\begin{array}{l}\text { esters, alcohols, fatty } \\
\text { acids and others }\end{array}$ & $\begin{array}{l}\text { Antibiofilm activity and inhibition of MRSA (three } \\
\text { clinical strains isolated from HIV infected patients) } \\
\text { biofilm production at a concentration of } 1000 \mu \mathrm{g} / \mathrm{mL}\end{array}$ & [68] \\
\hline 53. & Tanreqing injection & $\begin{array}{l}\text { Scutellariae radix, } \\
\text { Lonicerae flos, Forsythiae } \\
\text { fructus, Ursi fel, } \\
\text { Naemorhedi cornu }\end{array}$ & $\begin{array}{l}\text { flavonoids, phenols } \\
\text { and others }\end{array}$ & $\begin{array}{c}\text { MIC }=4125 \mu \mathrm{g} / \mathrm{mL} \text { for MRSA ATCC } 43300 \text {; strong } \\
\text { reduction in bacterial viability in mature MRSA } \\
\text { biofilms at } 1 / 2 \text { MIC and } 1 / 4 \mathrm{MIC}\end{array}$ & [69] \\
\hline 54. & Alcoholic extract & $\begin{array}{l}\text { Zanthoxylum armatum } \\
\text { DC. }\end{array}$ & alkaloids and others & $\begin{array}{l}>50 \% \text { inhibition of } S \text {. aureus UAMS- } 1 \text { biofilm } \\
\text { formation at } 256 \mu \mathrm{g} / \mathrm{mL} \text {, resulting from overall } \\
\text { growth inhibition at this dose }\left(\mathrm{IC}_{50}=32-256 \mu \mathrm{g} / \mathrm{mL}\right)\end{array}$ & [70] \\
\hline 55. & Essential oil & Rhanterium suaveolens & $\begin{array}{l}\text { alcohols, aldehydes } \\
\text { and others }\end{array}$ & $\begin{array}{l}\text { Highest antibiofilm activity of } 50.3 \% \text { against } \\
\text { S. epidermidis MU30 at } 20 \mu \mathrm{g} / \mathrm{mL} \text { essential oil }\end{array}$ & {$[71]$} \\
\hline 56. & $\begin{array}{l}\text { Aqueous plant } \\
\text { extracts }\end{array}$ & $\begin{array}{l}\text { branches of Bauhinia } \\
\text { acuruana, fruits of } \\
\text { Bauhinia acuruana, } \\
\text { leaves of Pityrocarpa } \\
\text { moniliformis, stem bark } \\
\text { of Commiphora } \\
\text { leptophloeos }\end{array}$ & $\begin{array}{l}\text { polyphenols } \\
\text { coumarins, terpenes }\end{array}$ & $\begin{array}{c}\text { Inhibition of biofilm production of } S \text {. epidermidis } \\
\text { ATCC } 35984 \text { at a concentration of } 4 \mathrm{mg} / \mathrm{mL} \text {, in a } \\
\text { range of approximately } 77-85 \%\end{array}$ & [72] \\
\hline 57. & Rhodomyrtone & Rhodomyrtus tomentosa & - & $\begin{array}{l}\text { MIC }=0.25-1 \mu \mathrm{g} / \mathrm{mL} \text { for } S \text {. aureus and } S \text {. epidermidis } \\
\text { clinical isolates; at } 0.5 \mathrm{MIC} \text { and } 0.25 \mathrm{MIC} \text { was found } \\
\text { to be effective in reducing biofilm formation in most } \\
\text { of the } S \text {. aureus isolates, At } 0.5 \mathrm{MIC} \text { rhodomyrtone } \\
\text { reduced biofilm formation in all six } S \text {. epidermidis } \\
\text { isolates, bactericidal effect in mature biofilm at } \\
64 \mathrm{MIC} \text { for } S \text {. epidermidis; rhodomyrtone } \\
\text { demonstrated better activity in killing the organisms } \\
\text { in } 24 \text { h biofilms than those in 5-day biofilms }\end{array}$ & [73] \\
\hline 58. & Skeletocutins A-L & $\begin{array}{l}\text { Skeletocutis sp. } \\
\text { (MUCL56074) }\end{array}$ & - & $\begin{array}{c}\text { Inhibition of S. aureus DSM1104 biofilm formation by } \\
\text { skeletocutin I: up to } 86 \% \text { at a concentration of } \\
256 \mu \mathrm{g} / \mathrm{mL} \text { and up to } 28 \% \text { at a concentration of } \\
150 \mu \mathrm{g} / \mathrm{mL}\end{array}$ & {$[74]$} \\
\hline
\end{tabular}

MIC (minimal inhibitory concentration); MSSA (methicillin sensitive Staphylococcus aureus); MBIC (minimal biofilm inhibitory concentration); $\mathrm{IC}_{50}$ (half maximal inhibitory concentration); $\mathrm{EC}_{50}$ (half maximal effective concentration); MTR (multidrug-resistance); VRSA (vancomycin-resistant Staphylococcus aureus).

Analyzing the presented results of published studies, it can be observed that the concentrations of active substances contained in products of plant origin are within the range of 0.1 to several thousand $\mu \mathrm{g} / \mathrm{mL}$, which indicates a large variation in their activity against biofilm. Different antimicrobial efficacy of the analyzed substances was also found depending on the age of the biofilm $[27,29,30,32,34,36,44,60]$. Mature structures are difficult 
to eliminate due to the accumulation of extracellular matrix and altered cellular metabolic activity. Such a phenomenon was noted, among others, in the study of Gondil et al. [75]. The second important feature of the analyzed substances is the increase of their activity, occurring proportionally to the increase of their concentration. Such a fact was observed for many substances, e.g., for psychorubrin, which caused inhibition of mature biofilms of S. aureus ATCC 33591, as well as for aurantioglycoladin, $\alpha$-mangostin, baicalein, and luteolin [41-43,46,48]. Similarly, aurantioglycoladin induced a concentration-dependent inhibition of biofilm production of $S$. epidermidis ATCC 35984. The inhibition of biofilm growth observed in some cases at concentrations of extracts higher than the MIC and even the $\mathrm{MBC}$, indicated that bacterial cells in biofilm are more resistant to antimicrobials, compared to cells growing in planktonic form. This is a well-known feature, confirmed in the present work for cinnamaldehyde, diterpenes, terpenoids, some flavones, norigenin, Vernonia condensata leaf extract, Olea europaea extract, and rhodomyrton [27,32,36,46,51,53,65,73]. Another observed phenomenon confirming the reduced activity of substances in relation to mature biofilm is the inhibition of this structure formation, occurring at a higher level than its eradication in the same concentration of the active substance-particularly evident in the case of 1-monolaurin, nerolidol, (+)-dehydroabietic acid, thymol, rosemary oil, and cinnamaldehyde $[26,27,29,36,60]$.

Within substances classified systematically into one chemical group, their antibiofilm activity was also significantly differentiated and required the use of individual substances in concentrations differing by several orders of magnitude to achieve the same efficacy. Such a phenomenon was observed for sesquiterpenes and diterpenes occurring in oleoresin from Copaifera duckei, methanol extract from aerial parts of Anthemis stiparum subsp. sabulicola as well as eugenol and nerolidol. The aforementioned substances, belonging to terpenes, showed differential activity against MRSA strains [28-31]. In the case of chalcones: xanthohumol and desmethylxanthohumol, extracted from the plant Humulus lupulus, the effectiveness of their action against mature and immature biofilm was differentiated. The concentrations of these compounds, resulting in inhibition of biofilm production, differed approximately tenfold [44]. A similar phenomenon, but of lower intensity, occurred for andrographolide and (+)-dehydroabietic acid, which both belong to the group of terpenoids. The inhibitory concentration of the formed biofilm for the mentioned compounds differed two-fold [33,36].

Luteolin, applied to a single-species $S$. aureus biofilm and a dual-species biofilm formed by $S$. aureus and L. monocytogenes, showed greater antibiofilm activity against the former. Such a phenomenon confirms the greater luteolin resistance of the dual-species biofilm compared to the single-species biofilm [48].

During the analysis, it was noted that flavonostilbenes exhibited stronger antimicrobial activity than flavonoids. The lowest growth inhibitory concentration (MIC) of naringenin (flavonoid) for S. aureus was 120-fold higher than the MIC for S. epidermidis of allopecurones (flavonostilbenes) [51,57]. Alopecuron D (flavonostilbenes) showed activity against biofilm formation at lower concentrations, but did not lead to death of all microorganisms [57]. On the other hand, diterpenes were more effective against the tested biofilm-forming pathogens compared to flavonoids, as evidenced by a higher percentage of reduction in biofilm formation [32].

The differential activity of plant-derived substances depending on the bacterial species was also confirmed. Differential activity of chelerythrine and sanguinarine was observed against $S$. aureus and $S$. epidermidis - twice lower $\mathrm{EC}_{50}$ for chelerythrine and six times lower $\mathrm{EC}_{50}$ for sanguinarine in case of $S$. epidermidis [66]. The terpenes contained in oleoresin from Copaifera duckei showed differential activity against S. aureus and S. epidermidis-MBIC about 12 times higher for S. aureus [30]. MIC analysis of methanolic extract from aerial parts of Anthemis stiparum subsp. Sabulicola showed about 25 times higher antibacterial activity against $S$. epidermidis, compared to $S$. aureus [31]. 


\section{Conclusions}

An important aspect of the analyzed substances of plant origin is their ability to have other biological activity, in addition to the presented antimicrobial activity. These substances possess anti-inflammatory, anticancer, and antioxidant properties [65,76-83]. The use of natural compounds in therapy is promising due to the occurrence of low natural resistance of microorganisms, but it carries some uncertainties. These include failure of therapy due to uncontrolled microbial growth or change in bacterial virulence. Natural antimicrobial compounds can also weaken the microbiota, causing bacterial dysbiosis, which is dangerous for the body. An ideal antimicrobial should selectively reduce the virulence-determining factors of a strain, without any toxicity to the macroorganism or the viability of the bacteria that make up its natural microbiota. The combination of multi-targeted action of antibiotics and antimicrobial substances has shown promising results against biofilm-producing bacteria. Interference of natural substances into host biochemical pathways is also encountered under certain conditions, which induces an increase in bacterial resistance to the host immune system. Structural optimization of natural products requires improved antimicrobial effects and reduced side effects based on knowledge of the mechanism of bacterial virulence, antibiotic resistance, and bacteria-host interactions. Natural antimicrobial products are a promising alternative as enhancers of drugs used against antibiotic-resistant bacteria [17].

Author Contributions: Conceptualization, D.S., R.D.W. and M.K.; Writing-original draft preparation, D.S., R.D.W. and M.K.; Writing - review and editing, A.K.-D. and R.D.; Visualization, D.S. and R.D. All authors have read and agreed to the published version of the manuscript.

Funding: This study was supported by the Medical University of Silesia. Grant number: PCN-2$019 / \mathrm{K} / 0 / \mathrm{K}$.

Data Availability Statement: No new data were created or analyzed in this study. Data sharing is not applicable to this article.

Conflicts of Interest: The authors declare no conflict of interest.

\section{References}

1. Otto, M. Staphylococcal biofilms. Microbiol Spectr. 2019, 6, 699-711. [CrossRef]

2. El-Baky, R.M.A. Application of Scanning Electron Microscopy for the Morphological Study of Biofilm in Medical Devices. In Scanning Electron Microscopy; Kazmiruk, V., Ed.; IntechOpen: Rijeka, Croatia, 2012; pp. 591-600.

3. Wu, E.C.; Kowalski, R.P.; Romanowski, E.G.; Mah, F.S.; Gordon, Y.J.; Shanks, R.M.Q. AzaSite Inhibits Staphylococcus aureus and Coagulase-Negative Staphylococcus Biofilm Formation In Vitro. J. Ocul. Pharmacol. Ther. 2010, 26, 557-562. [CrossRef] [PubMed]

4. Reffuveille, F.; Josse, J.; Vallé, Q.; Mongaret, C.; Gangloff, S.C. Staphylococcus aureus Biofilms and their Impact on the Medical Field. In The Rise of Virulence and Antibiotic Resistance in Staphylococcus aureus; Enany, S., Crotty Alexander, L.E., Eds.; Intech Open: London, UK, 2017. [CrossRef]

5. Polewczyk, A.; Janion, M.; Podlaski, R.; Kutarski, A. Clinical manifestations of lead-dependent infective endocarditis: Analysis of 414 cases. Eur. J. Clin. Microbiol. Infect. Dis. 2014, 33, 1601-1608. [CrossRef]

6. Bryers, J.D. Medical Biofilms. Biotechnol. Bioeng. 2008, 100, 1-18. [CrossRef] [PubMed]

7. França, A.; Gaio, V.; Lopes, N.; Melo, L.D.R. Virulence factors in coagulase-negative Staphylococci. Pathogens 2021, $10,170$. [CrossRef] [PubMed]

8. Kumar, A.; Prasad, R. Biofilms. JK Sci. 2006, 8, 14-17.

9. Mora, M.; Mahnert, A.; Koskinen, K.; Pausan, M.R.; Oberauner-Wappis, L.; Krause, R.; Perras, A.K.; Gorkiewicz, G.; Berg, G.; Moissl-Eichinger, C. Microorganisms in confined habitats: Microbial monitoring and control of intensive care units, operating rooms, cleanrooms and the international space station. Front Microbiol. 2016, 7, 1573. [CrossRef]

10. Dodds, D.R. Antibiotic resistance: A current epilogue. Biochem. Pharmacol. 2016, 134, 139-146. [CrossRef]

11. Jang, Y.S.; Mosolygó, T. Inhibition of Bacterial Biofilm Formation by Phytotherapeutics with Focus on Overcoming Antimicrobial Resistance. Curr. Pharm. Des. 2020, 26, 2807. [CrossRef]

12. Otto, M. Staphylococcal Biofilms. Curr. Top. Microbiol. Immunol. 2008, 322, 207-228.

13. Archer, N.K.; Mazaitis, M.J.; Costerton, J.W.; Leid, J.G.; Powers, M.E.; Shirtliff, M.E. Staphylococcus aureus biofilms. Properties, regulation and roles in human disease. Virulence 2011, 2, 445-459. [CrossRef] [PubMed]

14. Kranjec, C.; Morales Angeles, D.; Torrissen, M.M.; Fernández, L.; García, P.; Kjos, M.; Diep, D.B. Staphylococcal Biofilms: Challenges and Novel Therapeutic Perspectives. Antibiotics 2021, 10, 131. [CrossRef] 
15. De Vor, L.; Rooijakkers, S.H.M.; van Strijp, J.A.G. Staphylococci evade the innate immune response by disarming neutrophils and forming biofilms. FEBS Lett. 2020, 594, 1-14. [CrossRef] [PubMed]

16. Percival, S.L.; Emanuel, C.; Cutting, K.F.; Williams, D.W. Microbiology of the skin and the role of biofilms in infection. Int. Wound J. 2012, 9, 14-32. [CrossRef] [PubMed]

17. Wu, S.C.; Liu, F.; Zhu, K.; Shen, J.-Z. Natural Products That Target Virulence Factors in Antibiotic-Resistant Staphylococcus aureus. J. Agric. Food Chem. 2019, 67, 13195-13211. [CrossRef]

18. Dias, D.A.; Urban, S.; Roessner, U.A. Historical Overview of Natural Products in Drug Discovery. Metabolites 2012, 2, 303-336. [CrossRef]

19. Gorlenko, C.L.; Kiselev, H.Y.; Budanova, E.V.; Zamyatnin, A.A., Jr.; Ikryannikova, L.N. Plant Secondary Metabolites in the Battle of Drugs and Drug-Resistant Bacteria: New Heroes or Worse Clones of Antibiotics? Antibiotics 2020, 9, 170. [CrossRef]

20. Sen, T.; Samanta, S.K. Medicinal plants, human health and biodiversity: A broad review. Adv. Biochem. Eng. Biotechnol. 2015, 147, 59-110.

21. Porras, G.; Chassagne, F.; Lyles, J.T.; Marquez, L.; Dettweile, M.; Salam, M.R.; Samarakoon, T.; Shabih, S.; Farrokhi, D.R.; Quave, C.L. Ethnobotany and the Role of Plant Natural Products in Antibiotic Drug Discovery. Chem. Rev. 2021, 121, 3495-3560. [CrossRef]

22. Zacchino, S.A.; Butassi, E.; Liberto, M.D.; Raimondi, M.; Postigo, A.; Sortino, M. Plant phenolics and terpenoids as adjuvants of antibacterial and antifungal drugs. Phytomedicine 2017, 15, 27-48. [CrossRef]

23. Wang, Z.F.; Liu, J.; Yang, Y.A.; Zhu, H.L. A Review: The Anti-inflammatory, Anticancer and Antibacterial Properties of Four Kinds of Licorice Flavonoids Isolated from Licorice. Curr. Med. Chem. 2020, 27, 1997-2011. [CrossRef] [PubMed]

24. Sayout, A.; Ouarhach, A.; Rabie, R.; Dilagui, I.; Soraa, N.; Romane, A. Evaluation of Antibacterial Activity of Lavandula pedunculata subsp. atlantica (Braun-Blanq.) Romo Essential Oil and Selected Terpenoids against Resistant Bacteria Strains-Structure-Activity Relationships. Chem. Biodivers. 2020, 17, e1900496. [CrossRef]

25. Feng, D.; Zhang, A.; Yang, Y.; Yang, P. Coumarin-containing hybrids and their antibacterial activities. Arch. Pharm. 2020, 353, 1900380. [CrossRef]

26. Krislee, A.; Fadly, C.; Nugrahaningsih, D.A.A.; Nuryastuti, T.; Nitbani, F.O.; Sholikhah, E.N. The 1-monolaurin inhibit growth and eradicate the biofilm formed by clinical isolates of Staphylococcus epidermidis. BMC Proc. 2019, 13, 1-6. [CrossRef] [PubMed]

27. García-Salinas, S.; Elizondo-Castillo, H.; Arruebo, M.; Mendoza, G.; Irusta, S. Evaluation of the Antimicrobial Activity and Cytotoxicity of Different Components of Natural Origin Present in Essential Oils. Molecules 2018, 23, 1399. [CrossRef]

28. Yadav, M.K.; Chae, S.-W.; Im, G.J.; Chung, J.-W.; Song, J.-J. Eugenol: A Phyto-Compound Effective against Methicillin-Resistant and Methicillin-Sensitive Staphylococcus aureus Clinical Strain Biofilms. PLoS ONE 2015, 10, 1-21. [CrossRef]

29. Rubinia, D.; Banua, S.F.; Nishaa, P.; Muruganb, R.; Thamotharanc, S.; Percinod, M.J.; Subramania, P.; Nithyananda, P. Essential oils from unexplored aromatic plants quench biofilm formation and virulence of Methicillin resistant Staphylococcus aureus. Microb. Pathog. 2018, 122, 162-173. [CrossRef] [PubMed]

30. Vieira, R.G.L.; Moraes, T.D.S.; Silva, L.D.O.; Bianchi, T.C.; Veneziani, R.C.S.; Ambrósio, S.R.; Bastos, J.K.; Pires, R.H.; Martins, C.H.G. In vitro studies of the antibacterial activity of Copaifera spp. oleoresins, sodium hypochlorite, and peracetic acid against clinical and environmental isolates recovered from a hemodialysis unit. Antimicrob. Resist. Infect. Control 2018, 7, 1-13. [CrossRef]

31. Chemsa, A.E.; Zellagui, A.; Öztürk, M.; Erol, E.; Ceylan, O.; Duru, M.E.; Lahouel, M. Chemical composition, antioxidant, anticholinesterase, antimicrobial and antibiofilm activities of essential oil and methanolic extract of Anthemis stiparum subsp. sabulicola (Pomel) Oberpr. Microb. Pathog. 2018, 119, 233-240. [CrossRef]

32. Arora, D.S.; Mahajan, H. Major Phytoconstituents of Prunus cerasoides Responsible for Antimicrobial and Antibiofilm Potential against Some Reference Strains of Pathogenic Bacteria and Clinical Isolates of MRSA. Appl. Biochem. Biotechnol. 2019, 188, 1185-1204. [CrossRef]

33. Banerjee, M.; Parai, D.; Chattopadhyay, S.; Mukherjee, S.K. Andrographolide: Antibacterial activity against common bacteria of human health concern and possible mechanism of action. Folia Microbiol. 2017, 62, 237-244. [CrossRef] [PubMed]

34. Woo, S.-G.; Lee, S.-Y.; Lee, S.-M.; Lim, K.-H.; Ha, E.-J.; Eom, Y.-B. Activity of novel inhibitors of Staphylococcus aureus biofilms. Folia Microbiol. 2017, 62, 157-167. [CrossRef]

35. Haapakorva, E.; Holmbom, T.; von Wright, A. Novel aqueous oil-in-water emulsions containing extracts of natural coniferous resins are strongly antimicrobial against enterobacteria, staphylococci and yeasts, as well as on bacterial biofilms. J. Appl. Microbiol. 2017, 124, 136-143. [CrossRef] [PubMed]

36. Fallarero, A.; Skogman, M.; Kujala, J.; Rajaratnam, M.; Moreira, V.M.; Yli-Kauhaluoma, J.; Vuorela, P. (+)-Dehydroabietic Acid, an Abietane-Type Diterpene, Inhibits Staphylococcus aureus Biofilms In Vitro. Int. J. Mol. Sci. 2013, 14, 12054-12072. [CrossRef] [PubMed]

37. Danilova, T.A.; Danilina, G.A.; Adzhieva, A.A.; Minko, A.G.; Nikolaeva, T.N.; Zhukhovitskii, V.G.; Pronin, A.V. Effects of Miramistin and Phosprenil on Microbial Biofilms. Bull. Exp. Biol. Med. 2017, 163, 439-442. [CrossRef] [PubMed]

38. Vasconcelos, S.E.C.B.; Melo, H.M.; Cavalcante, T.T.A.; Júnior, F.E.A.C.; de Carvalho, M.G.; Menezes, F.G.R.; de Sousa, O.V.; Costa, R.A. Plectranthus amboinicus essential oil and carvacrol bioactive against planktonic and biofilm of oxacillin-and vancomycinresistant Staphylococcus aureus. BMC Complementary Altern. Med. 2017, 17, 1-9. [CrossRef] 
39. Burt, S.A.; Ojo-Fakunle, V.T.A.; Woertman, J.; Veldhuizen, E.J.A. The Natural Antimicrobial Carvacrol Inhibits Quorum Sensing in Chromobacterium violaceum and Reduces Bacterial Biofilm Formation at Sub-Lethal Concentrations. PLoS ONE 2014, 9 , e93414. [CrossRef]

40. Fontaine, B.M.; Nelson, K.; Lyles, J.T.; Jariwala, P.B.; García-Rodriguez, J.M.; Quave, C.L.; Weinert, E.E. Identification of Ellagic Acid Rhamnoside as a Bioactive Component of a Complex Botanical Extract with Anti-biofilm Activity. Front. Microbiol. 2017, 8, 496. [CrossRef]

41. Lemos, A.S.O.; Campos, L.M.; Melo, L.; Guedes, M.C.M.R.; Oliveira, L.G.; Silva, T.P.; Melo, R.C.N.; Rocha, V.N.; Aguiar, J.A.K.; Apolônio, A.C.M.; et al. Antibacterial and Antibiofilm Activities of Psychorubrin, a Pyranonaphthoquinone Isolated From Mitracarpus frigidus (Rubiaceae). Front. Microbiol. 2018, 9, 724. [CrossRef]

42. Yuyama, K.T.; da Costa Neves, T.S.P.; Memória, M.T.; Tartuci, I.T.; Abraham, W.R. Aurantiogliocladin inhibits biofilm formation at subtoxic concentrations. AIMS Microbiol. 2017, 3, 50-60. [CrossRef] [PubMed]

43. Meah, M.S.; Lertcanawanichakul, M.; Pedpradab, P.; Lin, W.; Zhu, K.; Li, G.; Panichayupakaranant, P. Synergistic effect on anti-methicillin-resistant Staphylococcus aureus among combinations of $\alpha$-mangostin-rich extract, lawsone methyl ether and ampicillin. Lett. Appl. Microbiol. 2020, 71, 510-519. [CrossRef]

44. Bocquet, L.; Sahpaz, S.; Bonneau, N.; Beaufay, C.; Mahieux, S.; Samaillie, J.; Roumy, V.; Jacquin, J.; Bordage, S.; Hennebelle, T.; et al. Phenolic Compounds from Humulus lupulus as Natural Antimicrobial Products: New Weapons in the Fight against Methicillin Resistant Staphylococcus aureus, Leishmania mexicana and Trypanosoma brucei Strains. Molecules 2019, 24, 1024. [CrossRef] [PubMed]

45. Qin, N.; Tan, X.; Jiao, Y.; Liu, L.; Zhao, W.; Yang, S.; Jia, A. RNA-Seq-based transcriptome analysis of methicillin-resistant Staphylococcus aureus biofilm inhibition by ursolic acid and resveratrol. Sci. Rep. 2014, 4, 5467. [CrossRef] [PubMed]

46. Zhang, S.; Hu, B.; Xu, J.; Ren, Q.; Wang, Z.; Wang, S.; Dong, Y.; Yang, G. Baicalin suppress growth and virulence-related factors of methicillin resistant Staphylococcus aureus in vitro and vivo. Microb. Pathog. 2020, 139, 103899. [CrossRef]

47. Omokhua-Uyi, A.G.; Abdalla, M.A.; Leonard, C.M.; Aro, A.; Uyi, O.O.; Van Staden, J.; McGaw, L.J. Flavonoids isolated from the South African weed Chromolaena odorata (Asteraceae) have pharmacological activity against uropathogens. BMC Complement. Med. Ther. 2020, 20, 233. [CrossRef] [PubMed]

48. Qian, W.; Liu, M.; Fu, Y.; Zhang, J.; Liu, W.; Li, J.; Li, X.; Li, Y.; Wang, T. Antimicrobial mechanism of luteolin against Staphylococcus aureus and Listeria monocytogenes and its antibiofilm properties. Microb. Pathog. 2020, 142, 104056. [CrossRef] [PubMed]

49. Abedini, A.; Colin, M.; Hubert, J.; Charpentier, E.; Angelis, A.; Bounasri, H.; Bertaux, B.; Kotland, A.; Reuveille, F.; Nuzillard, J.-M.; et al. Abundant Extractable Metabolites from Temperate Tree Barks: The Specific Antimicrobial Activity of Prunus avium Extracts. Antibiotics 2020, 9, 111. [CrossRef]

50. Chemmugila, P.; Lakshmia, P.T.V.; Annamalaib, A. Exploring Morin as an anti-quorum sensing agent (anti-QSA) against resistant strains of Staphylococcus aureus. Microb. Pathog. 2019, 127, 304-315. [CrossRef]

51. Zengin, G.; Menghini, L.; Di Sotto, A.; Mancinelli, R.; Sisto, F.; Carradori, S.; Cesa, S.; Fraschetti, C.; Filippi, A.; Angiolella, L.; et al. Chromatographic Analyses, In Vitro Biological Activities, and Cytotoxicity of Cannabis sativa L. Essential Oil: A Multidisciplinary Study. Molecules 2018, 23, 3266. [CrossRef]

52. Vasconcelos, M.A.; Arruda, F.V.S.; de Alencar, D.B.; Saker-Sampaio, S.; Ribeiro Albuquerque, M.R.J.; dos Santos, H.S.; Bandeira, P.N.; Pessoa, O.D.L.; Cavada, B.S.; Henriques, M.; et al. Antibacterial and Antioxidant Activities of Derriobtusone A Isolated from Lonchocarpus obtusus. Biomed. Res. Int. 2014, 2014, 248656. [CrossRef]

53. Da Silva, J.B.; de Bessa, M.E.; Santos Mayorga, O.A.; Andrade, V.T.; da Costa, Y.F.G.; de Freitas Mendes, R.; Pires Ferreira, A.L.; Scio, E.; Alves, M.S. A promising antibiotic, synergistic and antibiofilm effects of Vernonia condensata Baker (Asteraceae) on Staphylococcus aureus. Microb. Pathog. 2018, 123, 385-392. [CrossRef]

54. Li, K.; Han, X.; Li, R.; Xu, Z.; Pan, T.; Liu, J.; Li, B.; Wang, S.; Diao, Y.; Liu, X. Composition, Antivirulence Activity, and Active Property Distribution of the Fruit of Terminalia chebula Retz. J. Food Sci. 2019, 84, 1721-1729. [CrossRef] [PubMed]

55. Chusri, S.; Na Phatthalung, P.; Voravuthikunchai, S.P. Anti-biofilm activity of Quercus infectoria G. Olivier against methicillinresistant Staphylococcus aureus. Lett. Appl. Microbiol. 2012, 54, 511-517. [CrossRef] [PubMed]

56. Rasooly, R.; Molnar, A.; Choi, H.-Y.; Do, P.; Racicot, K.; Apostolidis, E. In-Vitro Inhibition of Staphylococcal Pathogenesis by Witch-Hazel and Green Tea Extracts. Antibiotics 2019, 8, 244. [CrossRef] [PubMed]

57. Wan, C.-X.; Luo, J.-G.; Ren, X.-P.; Kong, L.-Y. Interconverting flavonostilbenes with antibacterial activity from Sophora alopecuroides. Phytochemistry 2015, 116, 290-297. [CrossRef] [PubMed]

58. Schiavone, B.I.P.; Rosato, A.; Marilena, M.; Gibbons, S.; Bombardelli, E.; Verotta, L.; Franchini, C.; Corbo, F. Biological Evaluation of Hyperforin and Its Hydrogenated Analogue on Bacterial Growth and Biofilm Production. J. Nat. Prod. 2013, 76, $1819-1823$. [CrossRef] [PubMed]

59. Vaillancourt, K.; LeBel, G.; Yi, L.; Grenier, D. In vitro antibacterial activity of plant essential oils against Staphylococcus hyicus and Staphylococcus aureus, the causative agents of exudative epidermitis in pigs. Arch. Microbiol. 2018, 200, 1001-1007. [CrossRef]

60. Jardak, M.; Elloumi-Mseddi, J.; Aifa, S.; Mnif, S. Chemical composition, anti-biofilm activity and potential cytotoxic effect on cancer cells of Rosmarinus officinalis L. essential oil from Tunisia. Lipids Health Dis. 2017, 16, 190. [CrossRef]

61. Manzur, A.G.B.; Junior, V.S.M.; Morais-Costa, F.; Mariano, E.G.A.; Careli, R.T.; da Silva, L.M.V.; Coelho, S.G.; de Almeida, A.C.; Duarte, E.R. Extract of Mangifera indica L. leaves may reduce biofilms of Staphylococcus spp. in stainless steel and teatcup rubbers. Food Sci. Technol. Int. 2019, 26, 11-20. [CrossRef] 
62. Ouyang, P.; He, X.; Yuan, Z.-W.; Yin, Z.-Q.; Fu, H.; Lin, J.; He, C.; Liang, X.; Lv, C.; Shu, G.; et al. Erianin against Staphylococcus aureus Infection via Inhibiting Sortase A. Toxins 2018, 10, 385. [CrossRef]

63. Viktorová, J.; Kumar, R.; Rehorová, K.; Hoang, L.; Ruml, T.; Figueroa, C.R.; Valdenegro, M.; Fuentes, L. Antimicrobial Activity of Extracts of Two Native Fruits of Chile: Arrayan (Luma apiculata) and Peumo (Cryptocarya alba). Antibiotics 2020, 9, 444. [CrossRef] [PubMed]

64. Blando, F.; Russo, R.; Negro, C.; De Bellis, L.; Frassinetti, S. Antimicrobial and Antibiofilm Activity against Staphylococcus aureus of Opuntia ficus-indica (L.) Mill. Cladode Polyphenolic Extracts. Antioxidants 2019, 8, 117. [CrossRef]

65. Edziri, H.; Jaziri, R.; Chehab, H.; Verschaeve, L.; Flamini, G.; Boujnah, D.; Hammami, M.; Aouni, M.; Mastouri, M. A comparative study on chemical composition, antibiofilm and biological activities of leaves extracts of four Tunisian olive cultivars. Heliyon 2019, 5, e01604. [CrossRef] [PubMed]

66. Artini, M.; Papa, R.; Barbato, G.; Scoarughi, G.L.; Cellini, A.; Morazzoni, P.; Bombardelli, E.; Selan, L. Bacterial biofilm formation inhibitory activity revealed for plant derived natural compounds. Bioorg. Med. Chem. 2012, 20, 920-926. [CrossRef]

67. Maisetta, G.; Batoni, G.; Caboni, P.; Esin, S.; Rinaldi, A.C.; Zucca, P. Tannin profile, antioxidant properties, and antimicrobial activity of extracts from two Mediterranean species of parasitic plant Cytinus. BMC Complement. Altern. Med. 2019, 19, 82. [CrossRef] [PubMed]

68. Manilal, A.; Sabu, K.R.; Shewangizaw, M.; Aklilu, A.; Seid, M.; Merdikios, B.; Tsegaye, B. In vitro antibacterial activity of medicinal plants against biofilm-forming methicillin-resistant Staphylococcus aureus: Efficacy of Moringa stenopetala and Rosmarinus officinalis extracts. Heliyon 2020, 6, e03303. [CrossRef]

69. Yang, W.; Liu, J.; Blažeković, B.; Sun, Y.; Ma, S.; Ren, C.; Vladimir-Knežević, S.; Li, C.; Xing, Y.; Tian, G.; et al. In vitro antibacterial effects of Tanreqing injection combined with vancomycin or linezolid against methicillin-resistant Staphylococcus aureus. BMC Complement. Altern. Med. 2018, 18, 169. [CrossRef] [PubMed]

70. Khan, M.F.; Tang, H.; Lyles, J.T.; Pineau, R.; Mashwani, Z.; Quave, C.L. Antibacterial Properties of Medicinal Plants From Pakistan Against Multidrug-Resistant ESKAPE Pathogens. Front. Pharmacol. 2018, 9, 815. [CrossRef] [PubMed]

71. Chemsa, A.E.; Erol, E.; Öztürk, M.; Zellagui, A.; Özgür, C.; Gherraf, N.; Duru, M.E. Chemical constituents of essential oil of endemic Rhanterium suaveolens Desf. growing in Algerian Sahara with antibiofilm, antioxidant and anticholinesterase activities. Nat. Prod. Res. 2016, 30, 2120-2124. [CrossRef]

72. Trentin, D.D.S.; Giordani, R.B.; Zimmer, K.R.; da Silva, A.G.; da Silva, M.V.; Correia, M.T.D.S.; Baumvol, I.J.R.; Macedo, A.J. Potential of medicinal plants from the Brazilian semi-arid region (Caatinga) against Staphylococcus epidermidis planktonic and biofilm lifestyles. J. Ethnopharmacol. 2011, 137, 327-335. [CrossRef]

73. Saising, J.; Ongsakul, M.; Voravuthikunchai, S.P. Rhodomyrtus tomentosa (Aiton) Hassk. Ethanol extract and rhodomyrtone: A potential strategy for the treatment of biofilm-forming staphylococci. J. Med. Microbiol. 2011, 60, 1793-1800. [CrossRef]

74. Chepkirui, C.; Cheng, T.; Sum, W.C.; Matasyoh, J.C.; Decock, C.; Praditya, D.F.; Wittstein, K.; Steinmann, E.; Stadler, M. Skeletocutins A-L: Antibacterial Agents from the Kenyan Wood-Inhabiting Basidiomycete, Skeletocutis sp. J. Agric. Food Chem. 2019, 67, 8468-8475. [CrossRef] [PubMed]

75. Gondil, V.S.; Kalaiyarasan, T.; Bharti, V.K.; Chhibber, S. Antibiofilm potential of Seabuckthorn silver nanoparticles (SBT@AgNPs) against Pseudomonas aeruginosa. 3 Biotech. 2019, 9, 402. [CrossRef] [PubMed]

76. Kabała-Dzik, A.; Rzepecka-Stojko, A.; Kubina, R.; Wojtyczka, R.D.; Buszman, E.; Stojko, J. Caffeic acid versus caffeic acid phenethyl ester in the treatment of breast cancer MCF-7 cells: Migration rate inhibition. Integr. Cancer Ther. 2018, 17, 1247-1259. [CrossRef] [PubMed]

77. Miklasińska-Majdanik, M.; Kępa, M.; Wojtyczka, R.D.; Idzik, D.; Wasik, T.J. Phenolic compounds diminish antibiotic resistance of Staphylococcus aureus clinical strains. Int. J. Environ. Res. Publ. Health 2018, 15, 2321. [CrossRef]

78. Kabała-Dzik, A.; Rzepecka-Stojko, A.; Kubina, R.; Iriti, M.; Wojtyczka, R.D.; Buszman, E.; Stojko, J. Flavonoids, bioactive components of propolis, exhibit cytotoxic activity and induce cell cycle arrest and apoptosis in human breast cancer cells MDA-MB-231 and MCF-7-a comparative study. Cell. Mol. Biol. 2018, 64, 1-10. [CrossRef]

79. Kępa, M.; Miklasińska-Majdanik, M.; Wojtyczka, R.D.; Idzik, D.; Korzeniowski, K.; Smoleń-Dzirba, J.; Wąsik, T.J. Antimicrobial potential of caffeic acid against Staphylococcus aureus clinical strains. Biomed. Res. Int. 2018, 2018, 1-9. [CrossRef]

80. Iriti, M.; Kubina, R.; Cochis, A.; Sorrentino, R.; Varoni, E.M.; Kabała-Dzik, A.; Azzimonti, B.; Dziedzic, A.; Rimondini, L.; Wojtyczka, R.D. Rutin, a quercetin glycoside, restores chemosensitivity in human breast cancer cells. Phytother. Res. 2017, 31, 1529-1538. [CrossRef]

81. Kabała-Dzik, A.; Rzepecka-Stojko, A.; Kubina, R.; Jastrzębska-Stojko, Ż.; Stojko, R.; Wojtyczka, R.D.; Stojko, J. Comparison of two components of propolis: Caffeic acid (CA) and caffeic acid phenethyl ester (CAPE) induce apoptosis and cell cycle arrest of breast cancer cells MDA-MB-231. Molecules 2017, 22, 1554. [CrossRef]

82. Dziedzic, A.; Wojtyczka, R.D.; Kubina, R. Antimicrobial activity of berberine against cariogenic and opportunistic oral microorganisms. Int. J. Paediatr. Dent. 2017, 27, 20.

83. Miklasińska, M.; Kępa, M.; Wojtyczka, R.D.; Idzik, D.; Dziedzic, A.; Wassik, T.J. Catechin hydrate augments the antibacterial action of selected antibiotics against Staphylococcus aureus clinical strains. Molecules 2016, 21, 244. [CrossRef] [PubMed] 